\title{
Assessing the use and influence of sustainability indicators at the European periphery
}

\author{
Louis F. Cassar ${ }^{\mathrm{a}}$, Elisabeth Conrad $^{\mathrm{a}, *}$, Simon Bell $^{\mathrm{b}}$, Stephen Morse $^{\mathrm{c}}$ \\ a Institute of Earth Systems, University of Malta, MSD2080, Malta \\ ${ }^{\mathrm{b}}$ Communications and Systems Department, MCT Faculty, Open University, Milton Keynes MK7 6AA, United Kingdom \\ ${ }^{c}$ Centre for Environmental Strategy, University of Surrey, Guildford, Surrey GU2 7XH, United Kingdom
}

\section{A R T I C L E I N F O}

\section{Keywords:}

Sustainability indicators

Influence

Malta

Methodologies

Participation

\begin{abstract}
A B S T R A C T
Malta is a member of the European Union (EU), but faces constraints unique to its status both as a small island nation and its geographical location on the periphery of the EU. Several initiatives to develop suites of sustainability indicators (SIs) have been attempted in the Maltese Islands over the past two decades but there has been little corresponding follow-up to examine the extent to which such SIs are used by practitioners and influence policy. This paper presents an assessment of the use and influence of SIs in Malta by drawing upon the results of two quite different means of enquiry: (i) a more traditional approach in the social sciences using semi-structured and one-to-one interviews conducted with key stakeholders involved with SIs in Malta, and (ii) an innovative participatory approach, called Triple Task (TT) implemented within a workshop context, where stakeholders were placed in teams and asked to explore the use of SIs. Based upon the results obtained with these two methods of enquiry the paper provides insights into the problems of adoption of SIs in Malta and makes the case that rather than being seen as mutually exclusive, a combination of the two approaches provides a powerful means of triangulation to what is a complex set of issues.
\end{abstract}

(ㄷ) 2012 Elsevier Ltd. All rights reserved.

\section{Introduction}

The use of sustainability indicators (SIs) has become increasingly popular in strategic planning and policy-making (for example see: Rigby et al., 2000; Caddy and Seijo, 2005; Hezri, 2005; Hezri and Dovers, 2006; Rosenström and Kyllonen, 2007). There is, however, evidence to suggest that the actual use and influence of indicators is often modest or indeed entirely lacking (e.g. Bell and Morse, 2001; Rosenström, 2007; Turnhout et al., 2007), and can be hampered by a variety of barriers and obstacles. The latter may include both general factors related to the nature and design of indicators and of the policy-making/strategic processes, as well as factors related to the specific context within which SIs are used. The latter may include, for example, the state of sustainability strategic planning in the country, prior experience with indicator development and use, national policy, monitoring and reporting commitments, resource availability (Hezri, 2005; Bell and Morse, 2011) as well as the ways in which SIs are communicated (Chess et al., 2005) including the extent to which they are picked up and reported in the media (Morse, 2011). Hence, research relating to indicator use and influence needs to consider the geographical,

\footnotetext{
* Corresponding author.

E-mail address: elisabeth.conrad@um.edu.mt (E. Conrad).
}

economic and cultural context within which such tools are implemented.

Based on this premise, the paper explores issues of SI use and influence in the Mediterranean country of Malta. Whilst Malta is a full member state of the European Union it faces constraints unique to its status as a small island state and to its geographical location on the southern European periphery. Additionally, it is a recent entrant to the European Union (2004), and a country with a relatively young history of sustainable development; the first spatial planning and environmental management instruments only came into force in the early 1990s. Malta is also characterized by a heavily centralized governmental structure (Pirotta, 2001) which, coupled with the social dynamics of a small island society living for the most part in a highly urbanized context, can present unique challenges for sustainable development. These factors distinguish Malta from much of the European mainland, and arguably provide for a distinct experience with the implementation of sustainability planning.

This paper is based on the rationale that there may be contextspecific constraints to the use and influence of SIs and seeks to explore some of these within the island of Malta. Given the points made above, the island state provides an interesting context for exploring the assumption outlined above. However, it should also be noted that this provides something of a significant challenge given that the influence of SIs may not necessarily be direct in a cause-effect sense but may be far more subtle. Terms such as 'use' 
or indeed 'influence' can have a multitude of different meanings and thus are highly nuanced. Also of importance is the range of potential stakeholders who may be involved, spanning civil servants from various ministries as well as non-governmental agencies and the private sector. Thus the means by which the topic is explored can also be very important. After all, how the question is asked can have a significant influence on the answers received, a point exemplified in the classic paper published by Frances Griffiths in 1996. Preconceptions, reflexivity, theoretical frame of references all have an impact (Malterud, 2001) in social science research. Hence in order to explore the influence of SIs in Malta it was decided to follow two pathways, one employing the conventional social science method of semi-structured and individual interviews and the other utilizing a participatory approach called Triple Task (TT). Both approaches are qualitative rather than quantitative in nature (Crang, 2002), which may perhaps be ironic in the sense that SIs are of course for the most part numerical tools sometimes derived from quite complex arithmetical and statistical permutations. Conversely, however, the indicators (on the one hand), and the methods used for assessing their effectiveness (on the other) may (and do) pertain to different research paradigms. The additional, and at times alternative, depth and flexibility provided by qualitative methods can be seen to be challengingly suited to teasing out the nuances affecting indicator use and influence - especially, we would add, in contested contexts of discourse.

It was anticipated that the separate and blended outcomes from the two methodologies being used in this study (semi-structured interview/Triple Task) would yield some similar insights but also, potentially, some differences. Hence this paper has the key aim of providing an indication of the extent of use of SIs in the context of a small-island state on the periphery of Europe, and also seeks to draw inferences on their likely influence. Furthermore, the paper will show that the mode of enquiry may have an influence on answers obtained, through the use of two contrasting methodologies. The paper presents the findings arrived at from the two approaches separately before bringing them together into an overall picture of SI use in Malta.

The paper will begin by setting out the historical context of SIs in Malta. Although sustainable development has a short history in the country, there have been a number of SI initiatives and it is important to set these out for the reader. The paper will go on to describe the methodologies adopted for exploring the SIs that have arisen out of these initiatives and the influences that they may have had.

The research summarized in the paper was part of a larger project entitled POINT - Policy Influence of Indicators (Contract no. 217207, funded by the European Union FP7 Programme).

\section{Background to sustainability indicators in Malta}

There have been a number of initiatives for developing SIs in Malta in recent years, at both national and regional levels (Table 1). One of the early significant attempts at national scale was through the establishment of the Sustainability Indicators Malta Observatory (SI-MO). The aims of the observatory were to establish and increase capabilities for monitoring/reporting of environmental parameters and SIs in Malta. SI-MO developed a set of SIs based on a methodology proposed by the Mediterranean Commission for Sustainable Development (MCSD) (Cassar, 2006), in collaboration with the Malta National Office of Statistics. The 130 indicators identified within SI-MO, based on the MCSD guidance, were subsequently reduced to 100 , as (i) 3 indicators were found not to be relevant to the local context, and (ii) data for 27 other indicators could not be obtained (Cassar, 2010). During subsequent SI-MO activities, key concerns relating to SIs, and specifically to data availability and quality were observed, notably (i) lack of data in certain areas, (ii) lack of standardization and coherence in the way data were compiled, and (iii) variations in data provided by different agencies/departments.

The Blue Plan Coastal Area Management Programme (CAMP) project was a more regional-scale initiative, based in the north of the island (Bell and Morse, 2003). The 'Imagine' methodology utilized (Bell and Morse, 2001; Bell and Coudert, 2005; Larid, 2005; Bell, 2011) was designed to arrive at a list of SIs via participation with a range of local stakeholders, mostly comprising government staff from concerned ministries. Imagine was originally inspired by the soft systems approach of Peter Checkland (Checkland, 1981) and the ideas of a 'systemic sustainability analysis' set out in Bell and Morse (1999) which were founded on the key assumption that, given the complexity of sustainability and the fact that there are multiple perspectives, SIs are best developed with the participation of key stakeholders, including those meant to use them. The methodology evolved through a series of 'flavours' (variations on a theme), from Systemic Sustainability Analysis (SSA; the initial form or 'theoretical framework' of the approach) through to Systemic and Prospective Sustainability Analysis (SPSA) and finally Imagine. The overall aim throughout was to produce SIs in a manner which maximizes their chances of producing a holistic perception of the context in question, and in an inclusive and participatory manner (Plan Bleu, 2002).

The National Commission for Sustainable Development was set up in 2002, with one of its stated objectives being to review progress in the achievement of sustainable development. The outputs of the NCSD have included work on a National Strategy for Sustainable Development for Malta, covering the period between 2007 and 2016. The strategy was adopted by the National Commission for Sustainable Development in November 2006 following stakeholder consultation exercises. It should be noted, however, that the Strategy remains in draft format and at the time of writing has not yet been endorsed by Government. Indeed, in its present state, it is clearly noted that "the views expressed in the document do not necessarily reflect those of the Government of Malta". With regards to SIs, the strategy specifically notes that "the effective monitoring of sustainable development requires the compilation of appropriate indicators". The strategy further notes that although SIs have been compiled for Malta (as described above), there are still a number of issues that need to be addressed, in particular regarding institutional set-up, as at the time of writing, there is no state-funded body entrusted to develop SIs.

The National Statistics Office (NSO) also has a role to play in the monitoring of sustainable development in Malta. The NSO constitutes the executive arm of the Malta Statistics Authority. It includes directorates dealing with (i) economic statistics, (ii) business statistics (including environment and resources), (iii) social statistics and information society, and (iv) resources and support services, and is thus in a position to collect, analyze and present data relevant to sustainability. Some work on SIs has also been carried out by the Malta Environment and Planning Authority (MEPA), primarily as part of the compilation of State of the Environment reports and through relevant projects such as DEDUCE (Biblioteca de Catalunya-Dades CIP, 2007) (Table 1). MEPA is also represented on the National Commission for Sustainable Development.

Thus although sustainable development may be relatively new in Malta it can hardly be claimed that there has been little work with SIs. Indeed the raft of SI initiatives all taking place within a very short period and indeed within the context of a relatively small island state should arguably have had an influence. In other EU countries sustainable development has a longer history within policy and these countries tend to be larger both in terms of population and in the scales of their administrations. Malta thus represents a relatively small geographic and social space for SIs to be active. It 
Table 1

Key initiatives for the development of SIs in Malta.

\begin{tabular}{|c|c|c|c|}
\hline Date & Initiative & Responsible entity & Indicator suite \\
\hline 1995 & $\begin{array}{l}\text { Paper presented by Camilleri M. on } \\
\text { Sustainability Indicators for Malta }\end{array}$ & $\begin{array}{l}\text { International Conference on the } \\
\text { Planning and Integration of } \\
\text { Environmental and Economic } \\
\text { Planning in islands and small states }\end{array}$ & NA \\
\hline 2000 & $\begin{array}{l}\text { Establishment of Sustainability } \\
\text { Indicators Malta Observatory } \\
\text { (SI-MO) }\end{array}$ & $\begin{array}{l}\text { Foundation for International } \\
\text { Studies, University of Malta }\end{array}$ & $\begin{array}{l}\text { Total of } 100 \text { indicators relating to } \\
\text { (i) population and society, (ii) land } \\
\text { and areas, (iii) economic activities, } \\
\text { (iv) the environment, (v) } \\
\text { sustainable development: actors } \\
\text { and policies, and (vi) cooperation } \\
\text { in the Mediterranean }\end{array}$ \\
\hline 2000-2002 & $\begin{array}{l}\text { Coastal Area Management } \\
\text { Programme (CAMP): } \\
\text { implementation of 'Imagine' } \\
\text { methodology for participatory } \\
\text { design of SIs }\end{array}$ & Blue Plan & $\begin{array}{l}\text { The project focused on developing } \\
20 \text { indicators to be selected to } \\
\text { cover the key areas for the project: } \\
\text { 1. Sustainable Coastal } \\
\text { Management. 2. Marine } \\
\text { Conservation Areas. 3. Integrated } \\
\text { Water Resources Management. } 4 \text {. } \\
\text { Erosion/Desertification Control } \\
\text { Management and, 5. Tourism and } \\
\text { Health }\end{array}$ \\
\hline 2002 & $\begin{array}{l}\text { Drafting of National Strategy for } \\
\text { Sustainable Development for Malta }\end{array}$ & $\begin{array}{l}\text { National Commission for } \\
\text { Sustainable Development }\end{array}$ & $\begin{array}{l}20 \text { priority areas identified, with } \\
\text { accompanying SIs }\end{array}$ \\
\hline 2003 & $\begin{array}{l}\text { Symposium - Sustainability } \\
\text { Indicators for Malta }\end{array}$ & $\begin{array}{l}\text { Organized by SI-MO Malta at the } \\
\text { Foundation for International } \\
\text { Studies, Valletta, Malta 19th } \\
\text { February } 2003\end{array}$ & NA \\
\hline 2004-2007 & $\begin{array}{l}\text { DEDUCE - Développement durable } \\
\text { des Côtes Européennes - } \\
\text { INTERREG IIIC project }\end{array}$ & $\begin{array}{l}\text { Malta Environment and Planning } \\
\text { Authority }\end{array}$ & $\begin{array}{l}\text { Project focused on development of } \\
\text { indicators of Integrated Coastal } \\
\text { Zone Management }\end{array}$ \\
\hline $\begin{array}{l}\text { Reports compiled in multiple } \\
\text { years: } 1998 / 2002 \text { (less explicit } \\
\text { adoption of indicators within } \\
\text { broader report) } \\
2005 / 2006 / 2007 / 2008 / 2009 \\
\text { (explicit presentation of indicators) }\end{array}$ & $\begin{array}{l}\text { State of the Environment } \\
\text { Reports/Indicators }\end{array}$ & $\begin{array}{l}\text { Malta Environment and Planning } \\
\text { Authority and National Statistics } \\
\text { Office (Malta) }\end{array}$ & $\begin{array}{l}\text { Thematic foci include: (i) driving } \\
\text { forces for environmental change, } \\
\text { (ii) air, (iii) climate change, (iv) } \\
\text { land, (v) freshwaters, (vi) coastal } \\
\text { and marine environments, (vii) } \\
\text { resources and waste, (viii) } \\
\text { biodiversity, (ix) policy responses }\end{array}$ \\
\hline
\end{tabular}

is therefore perhaps timely to analyze the extent of use of SIs and their apparent influence, and to question what factors may have helped promote or hinder this. If there has been little use and/or influence, then why has this been the case given all the effort and resource that has been expended?

\section{Methodology}

\subsection{Semi-structured interviews}

\subsubsection{Selection of respondents}

The study sought to explore the perspectives of two categories of individuals: (i) those involved in the formulation and development of SIs, and (ii) those who could potentially make use of SIs in their profession. It should be noted that these two categories may also overlap, as specialists involved in SI design and production often subsequently make use of them in their work, and thus effectively pertain to both categories.

To this end, twelve respondents were purposely selected from amongst key public and private sector organizations involved in SI production/use. These included various directorates/sections within MEPA (including the Resource Management Unit, Policy Coordination Unit, and Information Management Unit, amongst others), the Ministry for Resources and Rural Affairs, the Malta Tourism Authority, the Office of the Prime Minister, the National Statistics Office, and environmental consultancies. The list of organizations above represents the most likely institutional users of SIs in Malta and was determined through a review of organizations with responsibilities pertaining to sustainability. Non-governmental organizations were not included in this sample.
All respondents held mid-level positions within their organization, and could exercise a degree of autonomy in their professional decisions; in order to ensure that all individuals met these criteria, respondents were selected on the basis of the professional contacts of two of the authors (LFC and EC) from the list of organizations above. Three respondents were involved solely in SI production/design, four respondents utilized SIs but had no input into their development, whilst the remaining five respondents were involved in the production of SIs, and also used them in their day-to-day work.

\subsubsection{Interviews}

Interviews were conducted in a semi-structured manner, i.e. whilst based on a pre-determined question guide (Tables 2 and 3), the discussion was allowed to evolve in a flexible manner, with additional questions raised as necessary during the interviews. Separate interview guides were developed for the two sets of respondents, albeit with some common questions; both interview guides addressed four main themes: (i) indicator use, (ii) indicator influence, (iii) possibilities for enhanced use/influence, and (iv) relevance to sustainable development in Malta. Each interview lasted approximately 45-60 min; interviews were conducted in November 2009. Semi-structured interviews are probably the most widely used approach to data collection in the social sciences. The fact that these are based on a central focus common to all interviews allows for comparisons to be made across cases; the individual nature of the interview, however, also allows the researcher to probe individual stories in more detail (DiCiccoBloom and Crabtree, 2006; Myers and Newman, 2007). Their advantage also rests with the depth of discussion and the fact that 
Table 2

Interview guide: potential users of sustainability indicators (SIs).

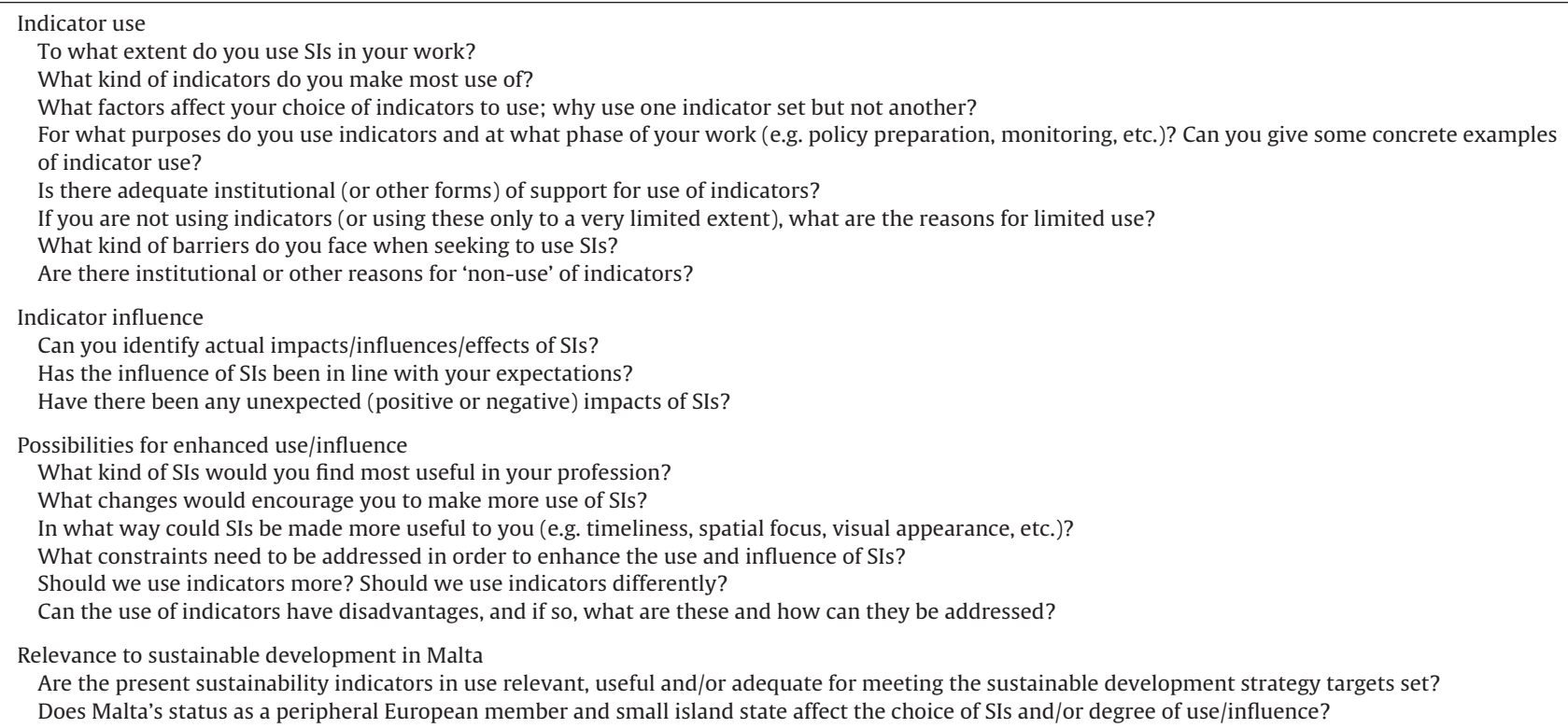

the discussion is flexible in the sense that while the researcher begins with a pre-determined set of questions there is scope for going beyond them, although it has to be said that much depends upon the skill of the researcher in being able to handle this. At the same time, as Myers and Newman (2007, p. 3) put it "the interview is a very artificial situation - it usually involves a researcher talking to someone who is a complete stranger." This may not always be the case, of course, and in a country as small as Malta, some degree of acquaintanceship is quite common. Still, the interview is an artificial process where the researcher is trying to gain as much information as possible within a relatively short time frame.

\subsubsection{Analysis}

Results were analyzed qualitatively, through thematic analysis and coding. The interview notes/transcripts were reviewed in order to identify key themes emerging during the discussion. Codes were thus not pre-determined but were derived inductively during the process of analysis; these were also revised and modified during several cycles of analysis and data review. It should be noted that the research design did not permit quantitative analysis.

\subsection{Triple Task (TT) methodology}

TT has three intertwined elements but for the purposes of this paper it is only necessary to describe one of them. The core of

Table 3

Interview guide: individuals involved in the production/design of sustainability indicators (SIs).

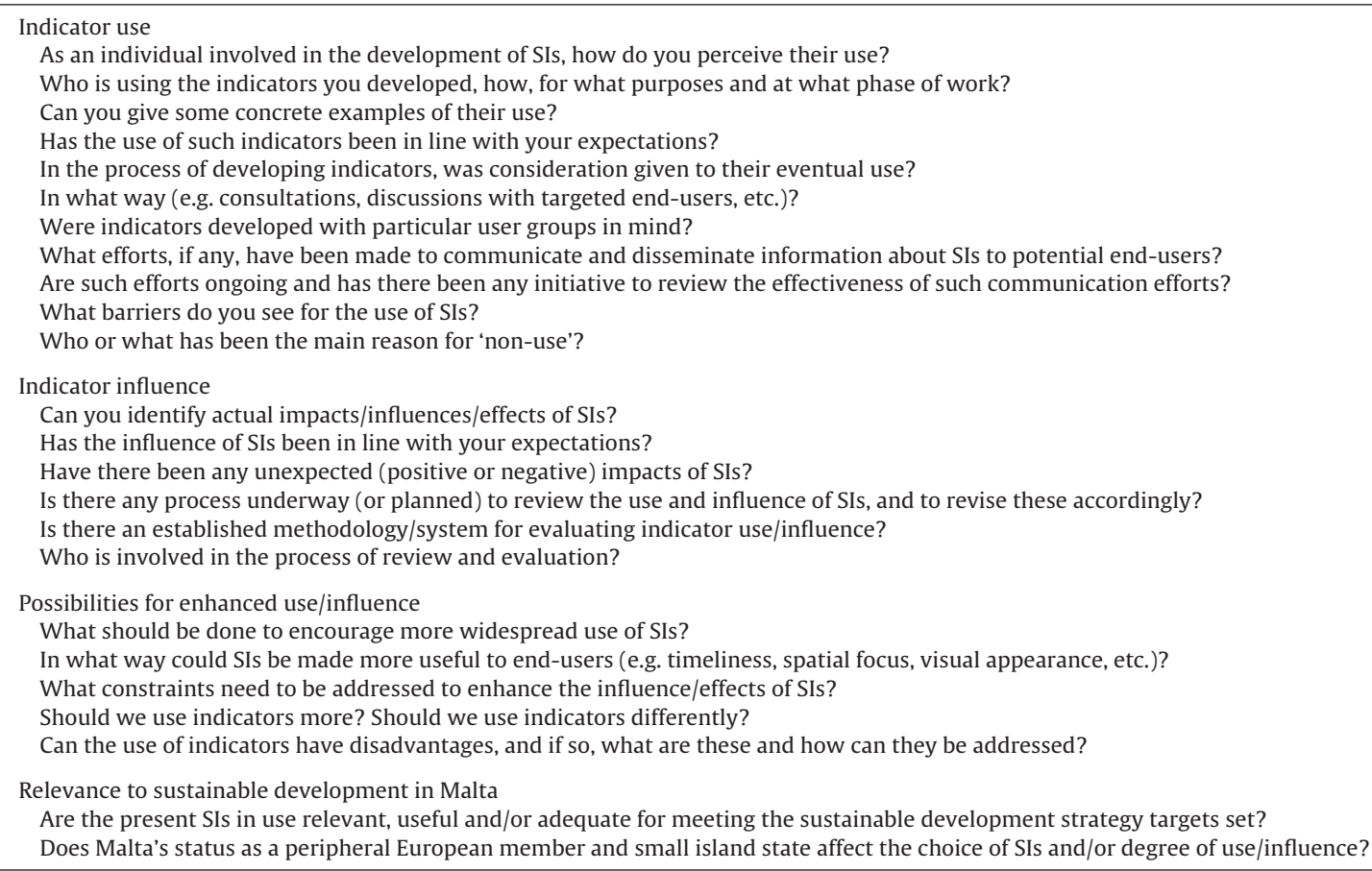


Table 4

Triple Task stakeholders - participant selection guide, based on a target group of 20-22 participants.

\begin{tabular}{|c|c|c|c|}
\hline & $\begin{array}{l}\text { Expected to be a daily/regular user } \\
\text { of indicators }\end{array}$ & Occasional/rare use of indicators & $\begin{array}{l}\text { Not a user of indicators but does } \\
\text { have knowledge of them }\end{array}$ \\
\hline Expert - could be a technical & ED & EO & EN \\
\hline $\begin{array}{l}\text { generator of indicators or a } \\
\text { regular user (at least in theory) } \\
\text { of specific indicators in policy } \\
\text { formulation. The obvious people } \\
\text { would probably be civil servants } \\
\text { but could include NGO or private } \\
\text { sector people. }\end{array}$ & 3 stakeholders & 3 stakeholders & 1 stakeholder \\
\hline Professional/practitioner - maybe & PD & $\mathrm{PO}$ & PN \\
\hline $\begin{array}{l}\text { a government/agency person or } \\
\text { an NGO/private sector person } \\
\text { who has a more applied and less } \\
\text { 'design' (technical) view of } \\
\text { indicators. }\end{array}$ & 4 stakeholders & 5 stakeholders & 2 stakeholders \\
\hline $\begin{array}{l}\text { Lay person - person 'in the street' - } \\
\text { could be keen but is at least } \\
\text { 'engageable' in conversations. }\end{array}$ & $\begin{array}{l}\text { LD } \\
2 \text { stakeholders }\end{array}$ & $\begin{array}{l}\text { LO } \\
1 \text { stakeholder }\end{array}$ & $\begin{array}{l}\text { LN } \\
1 \text { stakeholder }\end{array}$ \\
\hline
\end{tabular}

TT is derived from the 'soft systems' methodology of Peter Checkland, the psychoanalytic methods of Bridger and Klein and previous work by the authors on the SSA (Bell and Morse, 1999) and Imagine methodologies (Checkland, 1981; Checkland and Scholes, 1990; Klein, 2001, 2005; Bell and Coudert, 2005; Bridger, 2007). The underlying thrust within the core of TT is the same as that for SSA described earlier - the notion that complexity can best be appreciated by people who 'live' that complexity and thus understand the issues that rest within it, and that these groups, when provided with space to do so, are able to scope out that complexity and identify key issues and how best to handle them. Those attending the workshop held between the 3rd and 5th March 2009, 11-14 people in total (numbers fluctuated over the days), were selected on the basis of a pre-determined stakeholder guide (Table 4). During the workshop, participants were divided into two groups and asked to explore the factors which influence the use of indicators in policy. The two groups were given the codes 'A' and 'B'. Group A comprised a mix of government and NGO employees along with an academic and an environmental consultant. Group B was largely comprised of government employees and was as a result less diverse than the membership of Group A. It should be noted that there was no overlap between the respondent sample for the semi-structured interviews and those taking part in the workshop.

The workshop process followed a logical sequence which can be summarised as follows:

1. Scoping. All participants were asked to draw a rich picture (Bell and Morse, in press) which summarised their combined experience of the use of SIs to-date. The picture should represent a shared understanding, although in practice it is perfectly possible for a group to be dominated by an individual or individuals who impose their own vision from the onset or for a group to be fragmented with individuals drawing their own personal insight without any regard to the others. Whatever the coherence of the group, the rich picture is a mental map and thus is an essentially qualitative analysis and participants are encouraged to use the minimum of text.

2. Key tasks and issues. Participants are invited to draw out what they think are the major issues in their rich picture. There are likely to be many of these even within a relatively simple rich picture but it is necessary to begin a process of focusing on the key ones. The key issues are written onto Post-It stickers.

3. Systems of challenges. This is an extension of step 2 in that each group is asked to group related issues and provide them with catchy titles to indicate their main meaning. It is often the case that key issues will have a relationship and thus it is important for each group to contemplate any linkages. Each grouping is referred to as a 'system of challenge' (SoC).

4. Each group is invited to grade each of their SoCs in terms of both importance and the ease with which it may be addressed. One straightforward means of handling this is to ask each group to place their SoCs within a 2-dimensional matrix. This process helps the group identify SoCs that are important and relatively easy to address, and thus provides a basis for planning interventions and changes to address the issues.

5. The groups are asked to identify some of the important characteristics of a few SoCs selected from step 4, in effect to change the challenge into a desired transformation (a Vision of Change $-\mathrm{VoC})$.

6. Creation of action plans for each of the VoC statements. This sets out the practicalities of who needs to do what and when in order to achieve the VoC. In the case of the question posed to the groups at the start of the workshop, this stage would result in an action plan of the changes which could be achieved in order to make the use of indicators more effective in decision making.

7. Finally, each group is asked to 'close the circle' by producing a new rich picture which represents how the situation would look after the successful implementation of the changes brought about by step 6 . As part of this, the group is asked to look again at the rich picture it produced under step 1 and thus allows for an element of 'back-casting' by comparing the start point with the end point.

At various stages in the process the groups present their findings to each other and explain why they made the decisions they did. Notes were taken by the facilitators of each workshop based upon the written outputs and the explanations and discussions that took place amongst and between groups. These notes along with the outputs of the groups from steps 1 to 7 provided the basis for analysis.

Participatory methods such as TT also have their pitfalls and strengths, and these are well reported and discussed in the literature. For example, Campbell (2002) provides a concise review of some of them within the context of development research. They have the advantage of being participant-led rather than researcherled and thus can generate insights not known or even imagined by the research. Indeed the insights can 'emerge' from the participants' discussions and thus may not necessarily be known (a priori) to all of the participants. However, such approaches are lengthy ( 2 days for each TT workshop) and expensive and do not allow for comparisons between individuals who take part. As DiCiccoBloom and Crabtree (2006) have pointed out in the context of group 
discussions, these cannot be used as a seemingly 'quick' way to arrive at quasi-individual responses. Any insights provided by individuals within the workshops have been framed to some extent by their interaction with others.

\section{Results}

\subsection{Semi-structured interviews}

Results indicate that whilst various suites of SIs have been developed for use within Malta, there is generally limited use and application, and thus limited influence of SIs on strategic and policy decisions in the country. None of the respondents appear to use the suites of SIs which have already been established for the Maltese Islands (e.g. SI-MO, CAMP) and which are described in Section 2 above. When SIs are used this occurs primarily within one of four contexts.

First, SIs are used within certain international research projects in which organizations are participating as partners, and within which the design/use of indicators is 'built-in'. In such cases, the selection and design of SIs appears to have taken place by the international project team, and is not based on prior suites of SIs established for Malta. The time-frame of data collection is tied to the time-frame of the project (which generally ranges from two to five years). As a result, data collection (and related use of the developed SIs) generally ceases upon conclusion of the project, and the overall influence of SIs is thus limited. In effect the SIs are seen as a product of the project and die once the project has ended.

Second, SIs are also used to fulfil reporting obligations and for the dissemination of national-level data. In the former case, respondents most commonly cited Malta's requirements to provide data to the European Union related to various aspects of sustainability; in such cases, the selection of SIs is generally tied to the parameters established at European level, with limited scope for local selection. In the latter case, national data appears to focus disproportionately on economic indicators, with publication of various economic indices on a regular basis by the National Statistics Office; environmental and socio-cultural indicators are far more limited, although SIs have been used in recent State of the Environment Reports (see Table 1 and Section 2). Thus SIs are seen as being part of a somewhat 'mechanical' reporting process to a distant body rather than being relevant locally.

Thirdly, various respondents noted that the use of SIs for reporting/dissemination of national data tends to have a strategic element to it, with deliberate selection of SIs that portray a positive state of affairs. In this context, SIs therefore appear to be used in a 'marketing' or 'public relations' fashion rather than as tools to genuinely monitor progress (or lack of it) with a particular policy or intervention.

Finally, one respondent specified that she uses SIs as a matter of personal initiative, to enhance her professional work. It was, however, specified that such use of indicators is not mandated by the organization, and that there is in fact little (if any) coordinated organization-wide use of SIs.

Given the above, the meaning of 'use' is open to interpretation. There may be intense 'use' of SIs within a particular project timeframe but that evaporates once the project has ended. Given that projects may only 'live' for 3 years or less this hardly equates to any sort of longevity. Similarly, the need to report SIs can be seen as a 'use' in the sense of being a requirement to honour a commitment. However, both of these would hardly be seen as encouraging in terms of what most would regard as the real meaning of 'use' where SIs would be expected to help frame local (to Malta) decision making and for monitoring progress over time. Indeed this very limited use of SIs in Malta, despite the various initiatives that have taken place, raises questions as to why. Various factors limiting the use and influence of indicators were identified by respondents; these relate to the following broad thematic issues: (i) political and institutional priorities, (ii) data availability and quality, (iii) human and financial resources, and (iv) the specific context of the Maltese Islands.

Several respondents expressed their belief that there is little genuine political commitment to sustainability in Malta, notwithstanding the fact that sustainability figures prominently in political rhetoric - this observation was ironically most evident amongst those employed in the public sector. As a result, sustainability was deemed by respondents not to be a political priority, with the result that SIs are simply not considered to be of great importance. Here the 'use' of SIs was seen as having to follow an acceptance of sustainability rather than being seen as valuable in helping to promote it. One respondent argued that this laissez-faire rather than proactive stance was illustrated perfectly in the workings of the Malta Commission for Sustainable Development (which has not met for several years) and in politicians' lack of interest in the National Strategy for Sustainable Development (which remains in draft format, five years after it was first issued). It was argued that in this context, SIs are something of a 'lost cause' - with little potential to have a real influence on policy development and implementation at any scale in Malta. It is interesting to contrast this with the insights arrived at by Rydin (2007) where she noted the value of SIs in helping to frame sustainable development in parts of London and where they became part of the mediation of central-local government relations.

Institutional constraints were also highlighted by several respondents, who noted that there is a lack of commitment to monitoring of any sorts - the perception amongst interviewed professionals was that institutions tended to focus on developing and implementing policy and strategic planning initiatives, without a corresponding focus on monitoring the success of such initiatives and/or monitoring changes in the baseline system (the areas where SIs were felt to have a potential role). Again, such observations were most commonly made by those employed in public sector agencies. One respondent noted that monitoring was considered a low-level priority in general, and that this limits the likelihood of a strong commitment towards a sustained SI initiative. Respondents also noted that there is often too much bureaucracy to permit professionals to easily obtain data related to SIs, particularly when this is only available from another organization or from another unit within the same organization - this point was cited by both public and private sector respondents. It was furthermore noted that there is very little coordination and exchange across the different institutions involved in sustainability planning, with each pursuing its own 'niche' independently of the work carried out by other organizations. Some respondents highlighted a similar lack of coordination even within different arms of their own organization.

A key constraint highlighted by all respondents was the availability of continuous and good quality data. A major limitation appears to arise from the fact that SIs have generally been developed through research projects - and which applies to a number of the initiatives described in Section 2 above (e.g. SI-MO, CAMP) and that data were no longer collected after the conclusion of the project, with the result that there are only data 'blocks' covering short periods of time rather than a data series. As a result, there is in many cases a lack of continuous and up-to-date data, limiting the extent to which SIs can be used in practice for planning purposes. A second limitation relates to the specifics of certain identified SIs (i) which were deemed to be difficult to measure, (ii) for which data is not readily available, and/or (iii) which are considered to be inappropriate. Such constraints were identified by several respondents, in particular in relation to specific SIs listed in the National Strategy for Sustainable Development. Examples are the 
indicators identified under the Implementation priority area of the National Strategy for Sustainable Development, which include (i) an entity to coordinate the Sustainable Development Strategy process, and (ii) monitoring and evaluation tools, both of which are somewhat vague and which also fail to consider the effectiveness of such implemented measures. Concerns relating to data quality were also expressed. Several interviewees were sceptical about the quality of data obtained through certain research projects and/or by certain organizations, and expressed their reluctance to use such data as the basis for strategic planning.

One of the obstacles identified by the respondents for the poor sets of data series was that the sustained collection of data for SIs was not considered to be feasible in the short-term given issues of limited financial and human resources. Several respondents explained that their organization is already struggling to meet its existing workload with the capacity available, and that there was a need for a larger budget and more qualified staff. Respondents argued that substantial resources would be required to design SIs, collect data on a continuous basis, and establish initiatives for communication and dissemination, and that such resources were simply unavailable. Several respondents also explained that even using available SIs was difficult for them, as they simply did not have the time available to seek these out.

A specific resource constraint which was extensively discussed during the interviews stems from Malta's reporting obligations to the European Union. One respondent explained that his unit was focused almost exclusively on obtaining data to fulfil Malta's reporting requirements, with practically no capacity 'left over' for any other SIs. This was considered to be a negative phenomenon, because several European-level indicators were considered by respondents not to have much relevance for adaptive sustainability planning at the local level. Indeed, several professionals expressed their concern that Malta was investing considerable resources in collecting data for EU indicators, which are useful for large mainland countries but which are not useful for Malta. At the same time, there are no available resources to monitor issues which are of local relevance.

How would respondents address some of the constraints to SI influence that they had identified? Recommendations proposed by respondents focused primarily on revising the institutional setup related to SIs and sustainability planning. In particular, it was suggested that a centralized unit dealing with sustainability is established, to act as a coordination centre and clearing-house for all relevant data. The need for such a centralized system was reiterated by several respondents, who argued that SIs could not work in the present climate of 'organizational territoriality', where different entities are reluctant to share data. Such a unit would hold primary responsibility for ensuring that relevant data for SIs is collected, vetted for quality, and disseminated to potential end-users. Such a centralized unit should realistically, however, be established in conjunction with a clear workplan for the Malta Commission for Sustainable Development and an implementation programme for the National Strategy for Sustainable Development.

Recommendations were proposed to address specific constraints identified during the interviews, including (i) building the human and financial capacity of organizations involved in sustainability planning, (ii) establishing formal mechanisms for monitoring, and subsequent use of monitoring data for adaptive management, and (iii) establishing mechanisms for follow-up of research projects (including sustained data collection), to ensure that data is not merely available in 2-5 year 'blocks'. Respondents also argued for stronger synergies between public and private sector agencies involved in sustainability planning, and academia, arguing that universities could help organizations with their research needs and with relevant data collection for SIs. Several respondents also expressed the view that universities could
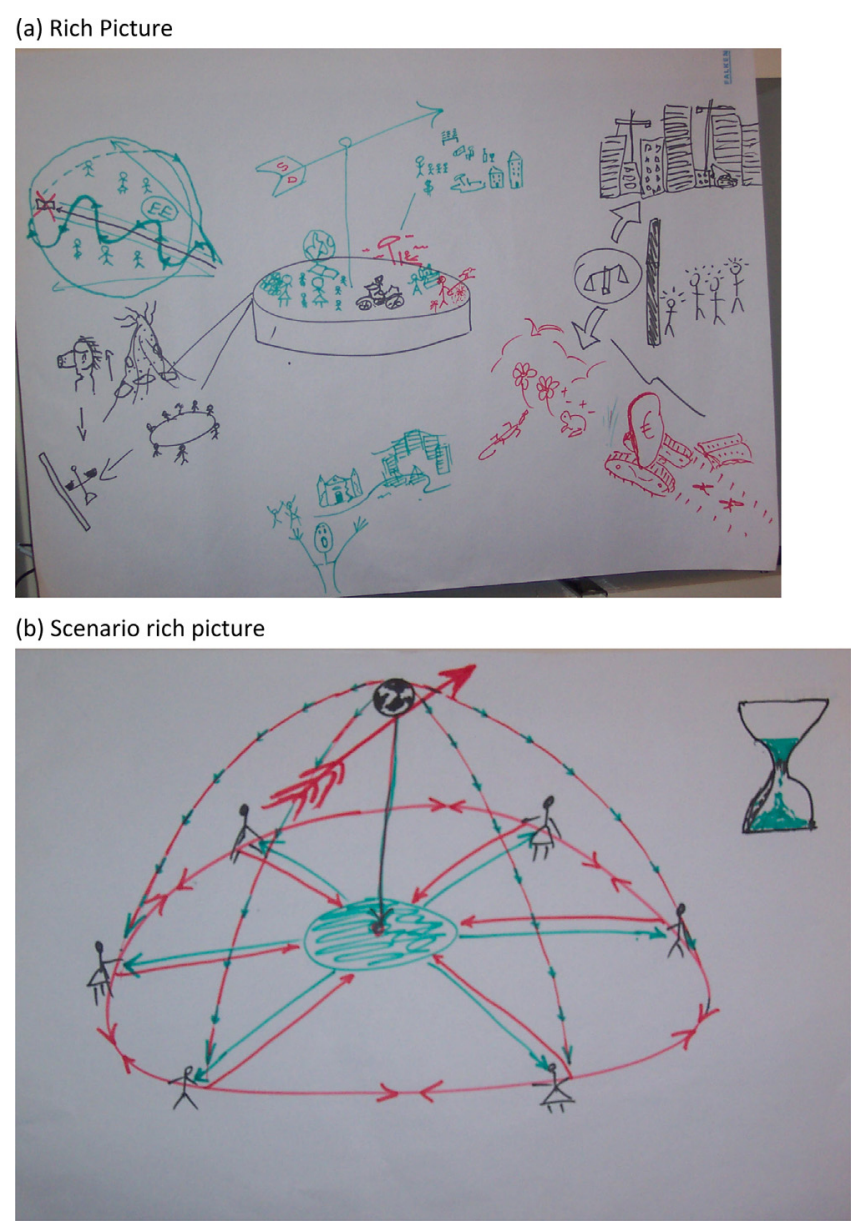

Fig. 1. Some of the outputs for Group A.

play a role in fostering a better understanding of the role and potential of SIs, both amongst professionals as well as amongst the public in general.

\subsection{Triple Task methodology}

There is no space here to present all of the outputs arising from steps 1 to 7 of the TT process for both groups but the rich pictures are presented as Figs. 1 (Group A) and 2 (Group B). In Fig. 1a, the rich picture the group created at the start of the workshop, there are various points of interest. First the story is a fractured one, with individuals in the group contributing corners of the picture. Thus the picture has a 'feel' of being fragmented, which may be an understandable reaction given the range of issues of relevance to sustainability in Malta. Each of these vignettes provides an interesting insight into indicator use but they were initially drawn as separate narratives. The central part of the picture is the weather vane, representing the ability of SIs to help identify direction in a range of sectors such as transport and construction (planning issues are quite prominent in Malta given the limited available space). The indicators are surrounded by a number of other issues important in Malta. Thus at the top right there is urban development and this is linked to issues of environmental destruction and dominance of economic concerns (bottom right). Towards the left hand side of the picture there is the issue of waste disposal. For an island as small and as densely populated as Malta this is an important issue and the landfill sites are an eyesore as well as providing a fire risk. An interesting vignette, even if a small one, is the scales of justice in the bottom left. The group did see justice as an important aspect underpinning elements of 


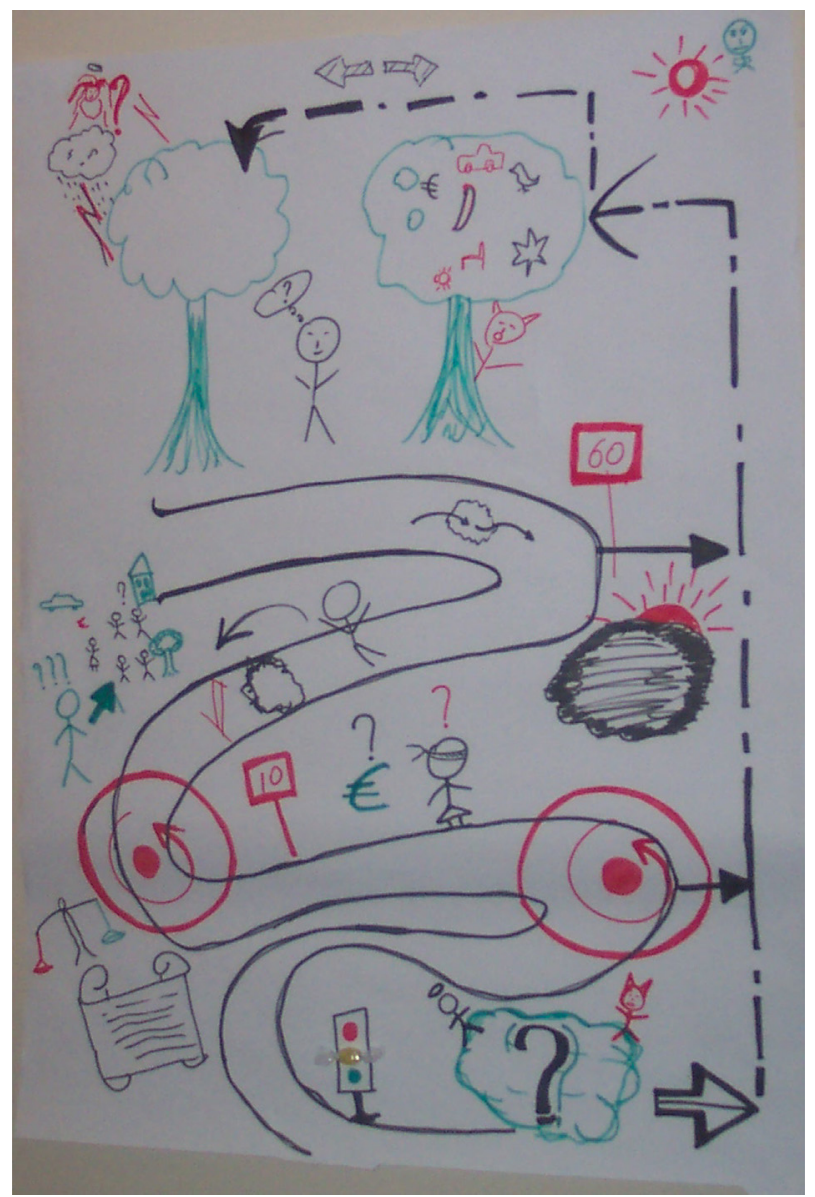

Fig. 2. The rich picture produced by Group B.

the picture, such that no one individual or group would be allowed to exploit available resources at the expense of others and SIs were seen as an important part of that. Towards the centre left of the picture is an interesting element, highlighting of the importance of education and the roles that indicators could play here. Indeed the process is a two-way one as education helps to make people aware of sustainability and indicators can help provide a more concrete representation of key ideas and processes. The latter has some resonance with the points made by Rydin (2007) and alluded to above. But there is a key aspect of will in here and this was something which the group stressed further as it progressed through the workshop. People have to care enough about sustainability in order for indicators to be accepted and used, but maybe one of the key factors which limits use is that people do not yet have the 'will' to change and thereby have the necessary SIs to help with that change. This is another way of expressing some of the points that came out of the interviews - the low ranking of sustainability in practice rather than rhetoric.

The problem with Fig. 1a is that the components of the picture are not joined up. Indeed when the picture was first drawn there were no links whatsoever and the group only added them in after they presented their picture and were asked what the links were. After going through the TT process it is interesting to note how the final rich picture is much more joined-up (Fig. 1b). The weather vane remains as the centre-piece of the picture, again representing the role of SIs in helping to identify direction, but this time it is surrounded by many connected issues and a hour-glass to represent the fact that time is running out and we need to move fast.

The rich picture for Group B is much denser than that of Group A and has a stronger and more coherent story, although at the same time a fairly familiar one. The road running through the centre of the picture represents that path from indicator development to indicator use, and along the way there are many obstacles. The potholes in the road represent blockages in indicator development. There are also speed limits, which suggest that development can progress rapidly at times before slowing down. Many of the symbols alongside the road represent the causes of such problems including political agendas, lack of finance and lack of awareness (blindfolded figure). Even when the end of the road is reached and an SI becomes accepted as being necessary, there are further issues of data collection represented by the trees at the top of the picture connected by a dashed line to the end of the 'indicator highway'. The tree on the left represents all the data that may be required, with the devil being in the detail. Overall the story being told by the group is almost a textbook representation of SIs with nothing that is especially exciting or novel.

\section{Discussion}

The main insights arising out of the research are summarised as Table 5.The semi-structured interviews provided several indications of limitations to the effective use of SIs in the Maltese context. All respondents indicated that the use and influence of SIs is not an issue that can be addressed in isolation, but, on the contrary, is intrinsically tied to broader institutional, political and economic influences. In particular, the use (or lack of use) of SIs was seen to be directly linked to political investment in and public demands for sustainability, both of which were considered to still be lacking in Malta. Furthermore, notwithstanding identified limitations with respect to data availability, the use of any existent data was seen to be further constrained by disparate organizational set-ups and ineffective communication amongst the various entities playing a role in sustainability planning. There was also an element of frustration amongst several respondents relating to the limited resources which professionals have at their disposal, and because of Malta's obligation to adhere to European reporting frameworks, which may not be the best suited for the local context.

Similarly, the TT approach generated a number of insights, some familiar ones while others are not so. Both groups stated that SIs can and should play a central role in policy and management. But people need to care about sustainability for them to be used, although this is something of a two-way street as SIs can also help with making people care. Infused throughout the discussions of both groups, but especially Group B, was the importance of consulting with stakeholders. In Malta it was felt that this was often poor - amounting to little more than a box ticking exercise - and needed to be improved. Part of this is to bring the issues of sustainability into education (Group A) and thus help create an indicator culture where people will demand them as a means of assessing the things that they care about. Also of concern to Group A was the importance of justice and the role that SIs could play. Group B were especially strong on issues of data availability and the need for quality data, although it was recognised that there were resource implications to this.

There was some broad agreement between the results of the two approaches (Table 5), with several key issues emerging independently from the two methodologies used. The interviews were more structured and focused, also allowing extensive discussion with individual respondents and as a result these generated more detail than the Triple Task workshops. The interview approach also allows for more comparison in findings between the people interviewed, and this can be very useful in terms of understanding positionality - where the respondents are 'coming from' and how that influences their analysis (DiCicco-Bloom and Crabtree, 2006; Myers and Newman, 2007). However, the process is controlled by the researchers as they set the questions and interpret the results. 
Table 5

Key themes emerging from the individual interview and Triple Task approaches.

\begin{tabular}{|c|c|c|}
\hline & Interviews & Triple Task \\
\hline \multicolumn{3}{|l|}{ Use of SIs } \\
\hline Limited use of SIs in Malta & $\sqrt{ }$ & $\sqrt{ }$ \\
\hline Strategic use of SIs & $\sqrt{ }$ & $\sqrt{ }$ \\
\hline Frustration with SI use & $\times$ & $\sqrt{ }$ \\
\hline Difference in perspective between stakeholder groups (e.g. public sector versus others) & $\sqrt{ }$ & $x$ \\
\hline \multicolumn{3}{|l|}{ Factors directly limiting use/influence } \\
\hline Limitations of data availability and quality & $\sqrt{ }$ & $\sqrt{ }$ \\
\hline Limitations of human and financial resources & $\sqrt{ }$ & $\sqrt{ }$ \\
\hline Limitations of political will to do sustainability & $\sqrt{ }$ & $\sqrt{ }$ \\
\hline Disjointed institutions and lack of organizational coherence & $\sqrt{ }$ & $x$ \\
\hline Professionals with no training/experience related to SIs & $\sqrt{ }$ & $\times$ \\
\hline Time-limited project-based SI initiatives & $\sqrt{ }$ & $x$ \\
\hline \multicolumn{3}{|l|}{ Underlying driving forces affecting SI use/influence } \\
\hline Political investment in sustainability & $\sqrt{ }$ & $\sqrt{ }$ \\
\hline Public awareness of sustainability/SIs & $\sqrt{ }$ & $\sqrt{ }$ \\
\hline Disconnect between indicator design and eventual end users/lack of stakeholder involvement in process of SI design & $\sqrt{ }$ & $\sqrt{ }$ \\
\hline Community demand for clarity about sustainability & $\times$ & $\sqrt{ }$ \\
\hline (In)adequate appreciation of the importance of monitoring & $\sqrt{ }$ & $x$ \\
\hline Lack of an adaptive management culture & $\sqrt{ }$ & $x$ \\
\hline \multicolumn{3}{|l|}{ Other relevant factors } \\
\hline Limited applicability of European-level indicators & $\sqrt{ }$ & $\times$ \\
\hline Disproportionate influence of economic indicators & $\sqrt{ }$ & $\sqrt{ }$ \\
\hline Inconsistent investment in sustainability/SIs over time & $\sqrt{ }$ & $\sqrt{ }$ \\
\hline Education as a major issue for SI development in future & $x$ & $\sqrt{ }$ \\
\hline SIs as a means of monitoring for justice & $\times$ & $\sqrt{ }$ \\
\hline
\end{tabular}

Issues of importance not raised by the researcher are in danger of being omitted unless the respondent breaks out of the pattern and mentions them. Individual-based processes such as interviews also provide little scope for learning between respondents. Indeed, the respondents may not meet at all or know who else is being interviewed.

The TT methodology is less restrictive as there is very little researcher influence. Indeed all the researcher does is provide a risk free space and minimal group steerage in terms of the 7 steps (which are designed to flow fairly spontaneously). Thus the groups are free to explore any avenue they wish and can generate emergent insights relevant to the issue. Hence, for example, Group A raised some more strategic issues such as education and justice that were not part of the interviews. However much depends upon factors such as the group dynamic. In the Malta workshop the two groups were quite different in terms of their make-up, with one being quite homogeneous (Group B) while the other was more diverse and had a number of strong and independent voices. The latter was most evident by the initial fractured nature of the rich picture compared with that of Group B. Yet perhaps surprisingly it was this initial fracture in Group A which seemed to allow them to look at the questions from novel angles while Group B tended to follow more of a 'text book' approach to indicators. Group A seemed to travel further and deeper into the complexity of the indicator issue than did Group B. A potential problem with participatory approaches such as TT is that they can tend to be too broad brush-stroke in nature, helping to highlight issues but having little scope for detailed exploration unless there is follow-up (Campbell, 2002). On the other hand, one of the benefits of participatory approaches is that they allow for learning between respondents to take place as well as networking (Bell and Morse, 2003). These can provide genuine insights which do not emerge from individual interviews and continued benefits once the workshop is finished.

Overall the results would suggest that SIs have a difficult future in Malta. The lack of a genuine commitment to sustainable development expressed by some of the respondents would seem to be a major challenge in itself but perhaps of almost equal relevance is the lack of a monitoring culture for developments. However, perhaps there is light at the end of a (albeit long) tunnel. While the routine reporting to the EU is problematic in terms of taking resources away from the local collection of SIs, it is nonetheless a commitment which the Maltese Government has to adhere to. Recent economic problems in the EU have highlighted the importance of good quality indicators as a means to avoid any significant problems from arising, and even if the requirements are imposed it does help to raise the profile of such reporting. SIs might be messy (Turnhout et al., 2007) but in many ways they are still the best tool in the box.

\section{Conclusions}

The research indicates that, within the Maltese context, SIs have so far failed to live up to their potential, having little evident influence on the policy process - indeed, while there has been investment in developing indicators, this appears to have been primarily an exercise 'in itself', rather than one linked to the eventual use of SIs in policy making and implementation. There is evidence to support the hypothesis of this paper, i.e. that the context within which SIs are implemented is a very relevant consideration. Malta appears to face significant challenges with sustainability planning in general, which constrain the use and influence of SIs. Additionally, Malta's peripheral European status and small island state qualities further influence the implementation of sustainability, and with that, the use of SIs.

The use of two methodologies provided a more rounded and comprehensive understanding of the factors affecting SI use and influence. The two approaches have together provided an interesting combination of both breadth and depth - from the strategic level to the detail of why SIs have yet to be accepted as useful tools in sustainable development policy and practice in Malta. Both methodologies have strengths and limitations - the approach adopted here draws on the relative advantages of both. It is of interest to note that certain key issues emerged independently from both research methodologies, whilst additional influences identified were specific to the individual approaches used (semi-structured interviews/Triple Task). Rather than being seen as contrasting, the two methodologies thus complemented each other, proving a means of triangulation (i.e. cross-checking of results) and allowing a more complete view of an essentially complex issue. 


\section{Acknowledgements}

The authors would also like to express their gratitude to all of their colleagues in POINT but especially Pia Frederiksen. The authors are also grateful to Mr. Robert Caruana, for assistance with data collection through the semi-structured interviews, and to Ms. Dorianne Cortis for logistical assistance with the organization of Triple Task workshops. We would also like to thank Dr. Ian Perry of the European Commission for his support.

\section{References}

Bell, S., 2011. From sustainable community to big society: ten years learning with the imagine approach. Int. Res. Geogr. Environ. Educ. 20 (3), 247-267.

Bell, S., Coudert, E., 2005. A Practioner's Guide to IMAGINE: The Systemic and Prospective Sustainability Analysis (Guide d'Utilisation pour IMAGINE: l'Analyse de Durabilité Systémique et Prospective). Sophia Antipolis, Blue Plan.

Bell, S., Morse, S., 1999. Sustainability Indicators. Measuring the Immeasurable. Earthscan, London.

Bell, S., Morse, S., 2001. Breaking through the glass ceiling: who really cares about sustainability indicators? Local Environ. 6 (3), 291-309.

Bell, S., Morse, S., 2003. Measuring Sustainability. Learning by Doing. Earthscan, London.

Bell, S., Morse, S. Rich pictures: a means to explore the 'sustainable mind'? Sustain. Dev., http://dx.doi.org/10.1002/sd.497, in press.

Bell, S., Morse, S., 2011. An analysis of the factors influencing the use of indicators in the European Union. Local Environ. Int. J. Justice Sustain. 16 (3) 281-302.

Biblioteca de Catalunya-Dades CIP, 2007. Indicators Guidelines: To Adopt an Indicators-Based Approach to Evaluate Coastal Sustainable Development, Available online: http://www.deduce.eu/PDF-NewsLetter/indicators_guidelines.pdf (last accessed: 25.09.11)

Bridger, H.,2007. The consultant and the consulting process. In: Handout at the Midhurst Working Conference. The Bayswater Institute, London.

Caddy, J.F., Seijo, J.C., 2005. This is more difficult than we thought! The responsibility of scientists, managers and stakeholders to mitigate the unsustainability of marine fisheries. Philos. Trans. R. Soc. Lond. B. Biol. Sci. 360, 59-75.

Campbell, J., 2002. A critical appraisal of participatory methods in development research. Int. J. Soc. Res. Methodol. 5 (1), 19-29.

Cassar, L.F., 2006. A landscape approach to conservation: integrating ecological sciences and participatory methods. PhD thesis. University of Reading.

Cassar, L.F., 2010. A Landscape Approach to Conservation: Integrating Ecological Sciences and Participatory Methods. International Environment Institute, Msida.

Checkland, P.B., 1981. Systems thinking. In: Systems Practice. Wiley, Chichester.

Checkland, P.B., Scholes, J., 1990. Soft Systems Methodology in Action. Wiley, Chichester.

Chess, C., Johnson, B., Gibson, G., 2005. Communicating about environmental indicators. J. Risk Res. 8 (1), 63-75.

Crang, M., 2002. Qualitative methods: the new orthodoxy? Prog. Hum. Geogr. 26 (5.), 647-655.
DiCicco-Bloom, B., Crabtree, B.F., 2006. The qualitative research interview. Med. Educ. 40 (4), 314-321.

Griffiths, F., 1996. Qualitative research: the research questions it can help answer, the methods it uses, the assumptions behind the research questions and what influences the direction of research. A summary of the panel discussion at the conference 'exploring qualitative research in general practice'. Fam. Pract. 13 (1), S27-S30.

Hezri, A., 2005. Utilisation of sustainability indicators and impact through policy learning in the Malaysian policy processes. J. Environ. Assess. Policy Manage. 7 (4), 575-595.

Hezri, A., Dovers, S., 2006. Sustainability indicators, policy and governance: issues for ecological economics. Ecol. Econ. 60, 86-99.

Klein, L., 2001. On the use of pshychoanalytic concepts in organizational social science. Concepts Transform. 6 (1), 59-72.

Klein, L., 2005. Working Across the Gap: The Practice of Social Science in Organizations. Karnac, London, New York.

Larid, M., 2005. Analyse de Durabilite dans le cadre du PAC Zone cotiere algeroise (Algerie). Sophia Anitpolis, Ministere de l'Amenagement du Territoire.

Malterud, K., 2001. Qualitative research: standards, challenges, and guidelines. Lancet 358 (9280), 483-488.

Morse, S., 2011. Harnessing the power of the press with indices. Ecol. Indicators 11 (6), 1681-1688

Myers, M.D., Newman, M., 2007. The qualitative interview in IS research: examining the craft. Inf. Org. 17 (1), 2-26.

National Commission for Sustainable Development, 2006. A Sustainable Development Strategy for the Maltese Islands 2007-2016, Available online: http:// www.um.edu.mt/_data/assets/pdf_file/0003/64812/SD_Strategy_2006.pdf (last accessed: 25.09.11).

Pirotta, G.A., 2001. A new creation or an image and likeness? The Maltese experience of establishing local government in a centralized micro-stat. Public Org. Rev., 245-260.

Plan Bleu, 2002. Final Report on the Systemic and Prospective Sustainability Analysis Project within CAMP Malta, Available online: http://www. planbleu.org/publications/pac_mlt_final.pdf (last accessed: 25.09.11).

Rigby, D., Howlett, D., Woodhouse, P., 2000. A Review of Indicators of Agricultural and Rural Livelihood Sustainability. Institute for Development Policy and Management, Manchester.

Rosenström, U., 2007. Exploring the policy use of sustainable development indicators: interviews with Finnish politicians. J. Transdiscip. Environ. Stud. 5 (1-2), $1-13$.

Rosenström, U., Kyllonen, S., 2007. Impacts of a participatory approach to developing national level sustainable development indicators in Finland. J. Environ. Manage. 84, 282-298.

Rydin, Y., 2007. Indicators as a governmental technology? The lessons of community-based sustainability indicator projects. Environ. Plan. D: Soc. Space $25,610-624$.

SI-MO, 2002. Final Report in Connection with MED-ERMIS (Mediterranean Environmental Reporting Monitoring and Information System) Malta, Covering the Period November 2000 to November 2002, Available online: http://www.um.edu.mt/islands/si-mo/AdminReports.html (last accessed: 25.09.11).

Turnhout, E., Hisschemoller, M., Eijsackers, H., 2007. Ecological indicators: between the two fires of science and policy. Ecol. Indicators 7 (2), 215-228. 